\title{
Demystifying student plagiarism in academic writing: Towards an 'educational' solution
}

\author{
Hloniphani Ndebele \\ Teaching and Learning Development Centre, Mangosuthu University of Technology \\ Corresponding Author: ndebele.hloniphani@mut.ac.za
}

(Submitted: 23 May 2020; Accepted: 19 November 2020)

\begin{abstract}
Plagiarism has become a recurrent challenge in higher education institutions, threatening the integrity of universities and their academic standards. The exacerbation of this issue can be largely linked to the escalating presence of online resources, which are easily accessible to knowledge and information communities worldwide. Many universities have thus instituted reactive measures that focus on detecting and policing plagiarism with little consideration of proactive and educational measures that can address the primary reasons for plagiarism and foster a community of academic integrity on their campuses. The purpose of this paper is, therefore, to interrogate the treatment of plagiarism in universities, and provide recommendations for better educational approaches to address this issue in proactive ways that also acknowledge the complex, contextual background of the South African higher education landscape. Understanding the primary reasons students plagiarise is critical in finding educational rather than punitive solutions to address the issue.
\end{abstract}

Keywords: academic literacies, curriculum, higher education, multilingualism, plagiarism

\section{Introduction}

Plagiarism has become a recurrent challenge in higher education institutions, not only in South Africa but around the world, which raises concerns about students' and staff academic development and the quality of professionals that universities produce. This challenge is largely linked to the escalating presence of online resources, which are easily accessible to knowledge and information communities worldwide. In addition to this issue, the recent COVID-19 pandemic has forced universities globally, and more specifically in South Africa, to move to online learning spaces, leaving universities in a quandary about how to deal with the problem of plagiarism, particularly with regard to online assessments. Plagiarism can be conceptualized as the action in which an individual copies and pastes borrowed text, insufficiently paraphrases text, and recites ideas without proper in-text citations and references to acknowledge from 
where they have borrowed information. Often such incidents of plagiarism are unintended; yet, there are also more intentional instances of this behaviour, which can be defined as "ghostwriting' in which students buy already written texts or have someone write their assignments and they present this work as their own for assessment purposes.

To address these issues, many universities across the globe have implemented a variety of strategies such as the following: a) having students submit their work via plagiarism detection software prior to assessment, b) formulating academic integrity or anti-plagiarism policies to sanction students who plagiarise, and c) teaching students about referencing skills. However, some scholars have argued that the development of plagiarism policies and the use of software tools to detect plagiarism have done little to reduce the incidence of plagiarism in the university context as many students engage in the practice out of ignorance and poor skills as opposed to intentional misconduct (Breen and Maassen, 2005). The inefficiency of these solutions illustrates that many universities are devising solutions to address this issue without considering the reasons behind the act of plagiarism (Sibomana, et al., 2018).

Given the limitations of many current solutions being implemented to address this issue, this article seeks to discuss whether the use of plagiarism detection software and other "policing" mechanisms are feasible solutions to promote a culture of academic integrity in the South African higher education context. Such a question is particularly important in the context of South Africa, which has experienced significant changes to its university landscape since the demise of apartheid in 1994. Although there are still visible traits of the apartheid legacy, access to higher education has improved tremendously regardless of race and gender (Pineteh, 2012; Archer, 2010). Yet, despite these changes, South African universities are under pressure to transform and perform, and this pressure has far reaching implications for teaching and learning in general and for student literacy practices, such as academic writing, more particularly. For example, with the massification of higher education, many students, particularly Black students, are struggling to maintain academic writing standards that are acceptable in the higher education. Of particular importance to highlight is that most South African higher education institutions have ignored inclusive pedagogies that acknowledge and promote a variety linguistic repertoires that a significant proportion of their student population bring to the classroom by solely relying on English to promote high order thinking skills and critical thinking as well as analytical and innovative skills (Pineteh, 2014). Thus, to explore the issue of academic integrity in this context, and the solutions that can be devised to promote a culture of academic integrity on South African university campuses, this article draws on the academic literacies framework (e.g. Street, 2004; Lillis and Scott, 2007; Carstens, 2012; Van Dyk and Van de Poel, 2013; Bailey, 2018) to argue that rather than conceptualizing and addressing all forms of plagiarism in the same way and responding with punitive solutions, we must first understand the reasons students commit such offenses in the first place and devise educational solutions that are preventive rather than reactive (De-Jager and Brown, 2010). 


\section{Plagiarism and its causes}

Literature on plagiarism shows that there is no universal definition of this particular issue, but rather what could be defined as two competing perspectives. The first perspective is one that is often more punitive, stemming from what Sharma (2007) explains can be traced to the Latin word 'plagiarius', which means a kidnapper or plunderer. Building on this notion plagiarism is perceived of a practice that involves using other people's ideas and texts while claiming original authorship and not acknowledging the source. Similarly, other scholars have conceptualised plagiarism as a form of 'misappropriation' through the unacknowledged use of words and/or ideas of another person (Mainka, et al., 2006), and academic misrepresentation and fraud through the presentation of another person's words or ideas as one's own (Badke, 2007). Within this vein, such acts are perceived as academic misconduct or dishonesty and often result in penalties such as fines, failure, public reprimands, suspension or expulsion from university (De-Jager and Brown, 2010).

In contrast to this more punitive conceptualization of plagiarism, other scholars have warned against the treatment of all forms of plagiarism as offences that result from intentional academic dishonesty (De-Jager and Brown, 2010). The second perspective of plagiarism is one that is less punitive and more developmental in nature, as it tends to acknowledge that plagiarism might not be a result of deliberate dishonesty, and instead stem from the enculturation process students experience as they learn how to write for academic and research purposes in the university context. It is in this process of trying to gain membership into their disciplinary communities that students may find themselves misrepresenting disciplinary conventions, and thus engaging in plagiarism because of a lack of understanding about how these conventions work not out of malicious intent.

These differing conceptualizations of plagiarism can result in confusion about the reasons why students commit violations in this regard. For instance, as Belter and du Pre (2009) explain, there are two primary reasons students commit plagiarism. The first reason is intentional deception, in which students recognize that their written work contains material that is not properly cited or quoted. Such students cheat because they perceive it is commonplace or they are uninformed about the consequences. The second reason is unintentional conduct and results from inadequate knowledge rather than wilful misconduct. An example of such a case could be students who fail to paraphrase ideas and to reference correctly. Such students can be unfairly brandished as plagiarisers or academically dishonest and sent to the university court. The thin line that differentiates between instances of intentional and unintentional plagiarism justify the need for an approach to the issue in which the goal is not to police students but rather capacitate and develop their abilities to engage in these key academic conventions in ways that are appropriate for their disciplines of study.

Plagiarism is further exacerbated by factors such as the easy availability of the internet and massification in South African universities and abroad. The spread and availability of information technologies has created a student body of digital natives who possess the ability to download a lot of online material with both intended and unintended consequences of 
plagiarism. In this regard, Anney and Mosha (2015) point to the rapid growth and improved access to the internet as a basic factor that has sophisticated student plagiarism and made it more tempting. In support of this view, Batane (2010) states that the ever ready availability of information in electronic and the billions of articles available on the internet makes it easy for students to copy and paste information into their assignments while, on the other hand, making it difficult for instructors to determine from where the information could have been extracted.

In addition, Mahabeer and Pirtheepal (2019) associate the problem of plagiarism with the massification of higher education in that it imposes a great deal of strain on post-secondary institutions, particularly with regard to the existing financial, physical and human resources. Such strains have resulted in teaching staff being able to spend sufficient teaching time with their students, negatively impacting the quality of education university students in the country receive (Mahabeer and Pirtheepal, 2019). Furthermore, the large number of students in classrooms make it difficult for lecturers to adequately deal with large volumes of assessments to be marked, and so quality of response and the academic integrity of student writing is compromised (Mahabeer and Pirtheepal, 2019). It is difficult to provide individual or at least timeous feedback in large classes because of the large numbers of students hence poor referencing techniques and other practices that may lead to plagiarism may persist without the student knowing. On the other hand, some students may take advantage of big class numbers to knowingly engage in acts of academic dishonesty through, for example, copy and pasting or submitting other people's work with a high likelihood of getting away with their actions.

While students may engage in plagiarism knowingly and unknowingly, there are a number of consequences associated with committing such acts in academic settings. Plagiarism can affect the reputation of an academic institution, its academics, and the graduates it produces. It can also be a stumbling block on students' creativity, originality, and ability to generate and contribute knowledge in their respective academic disciplines. Further, it can impede students' access to disciplinary discourses and communities through poor academic writing skills and a lack of understanding of disciplinary conventions. Further, plagiarism can lead to students incurring penalties, such as the deduction of marks, withdrawal of qualifications and sometime suspension from their studies. In support of the above, Strandler (2000) argues that the main purpose of education is to produce graduates who possess the ability to evaluate ideas through analysis, synthesis, and original thought, therefore a lack of such skills has a negative impact on academic standing and integrity.

\section{An overview of plagiarism studies in South African universities}

In South Africa, various studies have been conducted to understand the causes and the continued reoccurrence of plagiarism violations (for example, De Jager and Brown, 2010; Sentleng and King, 2012; Singh and Remenyi, 2016; Chrysler-Fox and Thomas, 2017; Thomas, Mahabeer and Pirtheepal, 2019; Mphahlele and McKenna, 2019). These studies point to numerous dynamics associated with the problems in South African higher education 
institutions. What is particularly interesting in these studies is the acknowledgement of plagiarism as both intentional and unintentional, and the need for an educational solution to the problem.

There seems to be a lack of consensus among universities and academics on how to deal with the problem of plagiarism when students writing for academic purposes. De Jager and Brown (2010), for example, investigated the problematic question of both intentional and unintentional student plagiarism, its causes, manifestation, and the different ways of addressing it. The study showed significant concern and engagement by academics in relation to the problem. The study further revealed a lack of consensus and inconsistency in dealing with the problem, as well as the issue of university academics tending to avoid official procedures and policies as they view them as lacking sensitivity to individual interpretation (De Jager and Brown, 2010).

The lack of consensus in dealing with plagiarism leads to much confusion and poor strategies of dealing with the problem, resulting in its persistence and increased ignorance among students. Such is evidenced in Sentleng and King's (2012) study which looked at instances of plagiarism among undergraduate students at a South African university with a major focus on the awareness and causes of plagiarism among first, second and third year students in the department of chemistry and mathematical technology. The findings of the study show that because of an immense lack of knowledge about plagiarism, students admit to copying and pasting from the internet to compile their essays (Sentleng and King, 2012).

Ignorance, a lack of knowledge about plagiarism and a lack of educational solutions to address the issue may result in students commiting more serious acts of plagiarism such as ghostwriting. As mentioned earlier, ghostwriting is when an individual enlists the services of another person to complete an academic writing task. This type of plagiarism which is largely intentional could be a result of a student's poor writing skills, laziness, a lack of knowledge on academic integrity, among other reasons. This is made clear in Singh and Remenyi's (2016) study which reviewed the current situation in South African higher education regarding plagiarism and ghost writing, particularly with regard to ghost writing practices that upper-year and graduate students resort to in order to complete their undergraduate and postgraduate dissertations and theses. The scholars found that instances of ghostwriting have become rampart in the South African university context such that it undermines the integrity of university to greater proportions. As a recommendation, Singh and Remenyi (2016) suggest creativity in teaching academic writing as well as open discussions about plagiarism to take place amongst universities' members of staff and student bodies.

As suggested above, educational interventions are a critical strategy for dealing with plagiarism. Such strategies should be aimed at capacitating students with critical skills of academic writing, create awareness of disciplinary conventions, referencing techniques, academic integrity and various ways of dealing with plagiarism. The importance of educational approaches in dealing with plagiarism was further evidenced by Chrysler-Fox and Thomas (2017) who investigated the impact of an intervention to address postgraduate student 
plagiarism in an honors programme at a higher education institution in South Africa. The study involved an examination of student essays for different forms of plagiarism at two different phases of a two-pronged developmental intervention. The findings of the study revealed that students who were involved in both stages of the intervention had fewer incidents of plagiarism in their essays compared to those who only attended one or no components of the intervention (Chrysler-Fox and Thomas, 2017).

In addition to educational interventions outlined above, some scholars have called for a re-think of assessment strategies in order to limit instances of student plagiarism. For example, instead of exclusively relying on summative assessments, academics can assess student learning through continuous, formative assessments, with student feedback key in this particular process. The importance of creativity in assessment methods is highlighted by Mahabeer and Pirtheepal (2019) in a study which explored the experiences of three emerging academics on assessment and plagiarism in the discipline of curriculum studies at a university in South Africa. The focus of the study was to understand how assessment and plagiarism are affected by large classes and the effect of the two factors on academic integrity. The findings of the study revealed that academics teaching large classes experienced high levels of student academic dishonesty, which compromised quality teaching and learning at their institutions. A rethink of assessment strategies in order to address academic dishonesty should be considered alongside the way academics and institutions think about plagiarism detection tools in teaching large classes. For instance, many South African universities require their students to use Turnitin to check for plagiarism in their assignments. However, in most cases, Turnitin is enforced by academics without any due consideration about the types of educational interventions that can be implemented to address plagiarism, which is unfair to students. In this particular regard, Mphahlele and McKenna (2019) investigated misunderstandings between the use of conventional methods of addressing plagiarism and the use of technology in South African higher education institutions. Their study revealed that most institutions have resorted to using technology, specifically plagiarism detection software, as a key tool of reducing plagiarism incidents. In this regard, these scholars argue that the Turnitin tool is misunderstood solely as a plagiarism detection tool for the purposes of policing; yet, it ignores the educational potential it has as a tool to develop university students' academic literacies. As such, an overreliance on Turnitin can deny students' access to the type of nuanced pedagogical interventions that may be critical in developing their abilities to write for academic purpose. In addition, an overreliance on Turnitin undermines the teaching of scholarly integrity because it assumes guilt and propagates an unsympathetic culture of deceit.

\section{Theoretical framework}

The study is conceptualised around the academic literacies model (Street, 2004; Lillis and Scott, 2007; Carstens, 2012; Van Dyk and Van de Poel, 2013; Bailey, 2018), particularly the notion that academic writing is expected to facilitate students' understanding of disciplinary discourses, their access to university culture, their negotiation of power relations, the construction of their 
individual identities and their abilities to construct both generic and disciplinary specific knowledge (Jones, et al., 1999; Bailey, 2018). The academic literacies model claims that student writing is based on 'relatively homogeneous norms, values and cultural practices' and it is a 'transparent medium of representation [which] is probably more appropriate for advanced students' (Archer, 2010: 497-498). Literacy is, therefore, seen as a set of social practices that deal with the construction of meaning from the perspective of student identities, power and relationships of institutional discourse and power in relation to what is viewed as appropriate and adequate (Carstens, 2012). As such, academic writing is a literacy practice that provides the link between students' entry into disciplinary communities and their acquisition of the formal conventions associated with the academy (Leibowitz, et al., 1997).

Central to the academic literacies model is also the importance of language in the students' experiences of learning (Lillis, 2001). It is argued that language plays a significant role in the development of subject learning, assessments, and the understanding of formative feedback (Bailey, 2018). As such, learning is a social and cultural process, and 'people learn best when their learning is part of a highly motivated engagement with social practices which they value' and that 'space" is a constructive concept for understanding how learning occurs'. (Gee, 2004: 77). This model further holds the belief that the literacy demands of the curriculum require various communicative practices (Street, 2004). As such, student learning should be structured in a way that will enable them to switch practices between settings, genres and disciplines, rendering them capable of transferring knowledge as part of the community of academic practices (Van Dyk and Van de Poel, 2013). The following sections explore whether and how universities' approaches to academic integrity ( $\mathrm{Al}$ ) and preventing instances of plagiarism are developmental in nature and aligned with the academic literacies framework or more punitive, reactive and oppose this theoretical lens.

\section{Implications a 'detecting and policing' approach to plagiarism}

Institutions of higher learning, and in particular academics, in Africa cannot turn a blind eye to students' literacy and linguistic backgrounds, and the continued dominance of English as the de-facto language of teaching and learning in South African universities despite the linguistic diversity manifested in classrooms. The continued overreliance on the Turnitin software, a software used to check originality in a text and plagiarism prevention, alongside plagiarism policies and penalties to deal with the problem of plagiarism seem to worsen the situation rather than helping it. Turnitin does not necessarily detect plagiarism but similarity and, in most cases, is not used in the way it was originally intended, which was as a tool to guide students in their writing rather than a policing application. It has been argued that identifying plagiarism is not an easy task, and even software tools, such as Copycatch or Turnitin, are not effective in all contexts (Sharma, 2007). While Turnitin can assist in detecting some instances of plagiarism, it does not develop students' writing abilities by offering any solutions to the problem, thus creating, in many cases more problems than solutions. In this regard, scholars have highlighted the weaknesses of the Turnitin software, questioning its reliability in terms of determining if a 
text is plagiarised (Noynaert, 1997; Savage, 2004; Mulcahy and Goodacre, 2004); hence, its use does not help students develop their abilities in academic writing. Noynaert (1997) states that the software tends to deem that a text is plagiarised even though it lacks the capacity to scrutinise reports for accuracy. As such, instances of coincidental plagiarism in which students may unknowingly use similar words that have previously been used, particularly in common research areas may be unjustifiably deemed instances of plagiarism (Savage, 2004). These instances of inaccuracies explain why academics themselves have a responsibility to carefully assess students' assignments to make better judgements as opposed to sole reliance of the software to do the work.

The software also has limitations in that it also lacks the capability of checking everything on the internet, for example some computer programmes and images (Batane, 2010). In addition, the databases for the software contain only material found on the web, and worse still, not all of it, and the software is not capable of identifying paraphrased text (Mulcahy and Goodacre, 2004). Further, in a study conducted by Savage (2004), students argued that by submitting work to the software, the automatic assumption is that all who submitted are guilty until proven innocent thus contradicting the principle of justice which assumes that a person is innocent until proven guilty. Often, Turnitin is used by academics to check if students have cheated rather than for students to check their work. The implication of this negative assumption is that the use of Turnitin by academics and their institutions constrains students' confidence and literacy development by rendering them incapable of independent thought and critical evaluation of sources before they can even prove themselves. All these examples illustrate that Turnitin is, in many cases, not being used for the educational purposes for which it was developed.

In addition to these challenges, Turnitin can also easily be manipulated, for example, through paraphrasing texts. Paraphrasing a text is not an easy task, particularly if one has not been taught how to engage in this activity and does not have a strong command of language use in that particular discipline. In order to bridge such a gap, students may resort to the use of online paraphrasing software tools which are accessible for free. This use, therefore, creates more problems than solutions by promoting creative dishonesty as students try their best to avoid being caught and face possible penalties. Forcing students into a situation whereby they are left with no choice but to engage in dishonest ways to dealing with their academic work contradicts the fact that apart from imparting knowledge to students, universities also have a responsibility of imparting ethical and moral values, which are important to the political, economic and social fabric of any successful society (Batane, 2010).

Given the ambiguity of plagiarism, characterised by contradictory definitions and interpretations, overreliance on detecting and policing plagiarism disadvantages students in various ways. What is important to highlight is that learning is a process and the acquisition of an academic discourse takes a long time, hence students who are not familiar with the discourse of their disciplines, particularly when they are working in their additional language, may unknowingly write using other people's words without referencing. For example, what is 
often conceptualised as common knowledge, which is not viewed as a case plagiarism, can be confusing, thus indicating cultural bias (Sibomana, et al., 2018). Differentiating between what is viewed as common knowledge and what is attributable to first sources is a difficult task-a difficulty that can be further compounded for students who are still learning disciplinary conventions and discourses to trying to gain membership into their disciplinary communities. It is in this process of learning and familiarization with new discourses that students find themselves unknowingly engaging in plagiarism, and plagiarism detection software often do not take cognisance of such dynamics. It is therefore safe to state that the challenges that students experience in writing and learning should be considered at the level of discourses, disciplinary practices and epistemology as opposed to inadequacies that require remedial interventions (Bailey, 2018). Similarly, academics need to also consider how knowledge is constructed in their disciplines and how this information can be made more explicit to students to ensure they can effectively address students' expectations in relation to appropriate writing practices (Bailey, 2018).

The authority of some academics and leading scholars in particular disciplinary fields limit students by expecting them to write in particular ways. Such expectations and requirements discourage students from actively interpreting discourses and thus resort to replication of what their lecturers want because of the fear of writing what will be rejected (Hebb, 2002). In such situations, students assume that putting the author's ideas in their own words could distort the 'esteemed ideas' of the authorities, and disciplinary discourses remain distant from them as they cannot make changes or own it (Sibomana, et al., 2018). Van de Poel and Gasiorek (2012: 294) agree with the above, and stress that

... there is a persistent gap between staff and student expectations with respect to what is considered "good" academic writing ... Students often do not know what qualities their instructors are looking for in their writing, and as such do not have confidence in their ability to write in [and for a particular] context.

\section{Literacy development as an approach of curbing plagiarism}

Given these ideas stemming from the field of academic literacies, a key point in this article is that plagiarism cannot be viewed in isolation but should be understood within the context of literacy practices, the students' linguistic capital and the language of teaching and learning, English. Haggis (2006) challenges institutions of higher learning to adopt a holistic approach to develop students' abilities to write and communicate for academic purposes by not focusing entirely on perceived deficiencies among students and ways to accommodate them, but the many aspects of the higher education experience that can be adjusted. Specifically, there is a need to focus on and identify potential barriers in the curriculum and then adopt pedagogies that embrace student diversity (Haggis, 2006). According to Wingate (2006), students in higher education need strong support with both the linguistic and stylistic forms and the tacit conventions surrounding academic writing such as critique, evaluation, appropriate support 
and referencing and making content relevant to the question and the discussion expected. If students are not supported in this regard, it is highly likely that they may unknowingly engage in plagiarism. As such, it is important for academics to counter such early, particularly at first year level by employing a number of interrelated interventions and methodologies.

To start with, evidence shows that irrespective of the medium of instruction, most university students in South Africa, especially those who come from poor socio-economic backgrounds, the majority of whom are black African students due to historical reasons, lack advanced academic language and literacy skills (Mgqwashu, 2014; Mothlaka and Makalela, 2016). Because English is the medium of instruction in most South African institutions, poor English language and literacy skills have a devastating effect on these students. The South African school system is to blame for poor English language and literacy skills because the context in which many children in South Africa acquire English does not favour the African child. Realistically, one cannot expect, for example, an approach used to teach a middle class child in a former 'White' suburb like Rondebosch in Cape Town to be the same as that employed to teach a poor working class child in a township like Khayelitsha in Cape Town (Desai, 2016). This is particularly the case because the socio-economic and cultural background of students has an influence on their learning needs and further shapes their learning habits.

In order to address the above challenges, academics should consider embedding issues of academic integrity, plagiarism, and academic writing in their teaching of disciplinary content.

The course outline should define concepts of plagiarism and provide explanation on what ways plagiarism is illegal and the different ways of preventing it. In addition, students could be exposed to cases and samples of plagiarised work while also engaging them in open forum classroom discussions on the issue. Academics could collect, at the beginning of their modules, samples of students' language and writing as a useful strategy of developing a point of reference. Furthermore, universities should also consider instituting online academic integrity modules, through their writing centres and academic literacy support units, in order to reduce the occurrence of plagiarism in written assignments. In such an online module, a minimum pass mark could be enforced, and students allowed to redo the module until they achieve the required mark.

Secondly, it is important to highlight that classrooms in South African universities are largely multilingual, and learners have to negotiate their social and cultural capital in order to acquire the language of teaching and learning as a medium of communication (De Kock, et al., 2018). For black African language speaking students, such negotiation is an uphill task which is further complicated by continued disregard of their $1^{\text {st }}$ language in preference for English as the de-facto language of teaching and learning. Yet, research has proven that any kind of an education system that does not acknowledge a variety of linguistic capital and repertoires that the student brings into the classroom serves no other purpose but to impede the academic development and rights of students (Heugh and Skutnabb-Kangas 2010; Hornberger, 2003). As such, 'people learn best when their learning is part of a highly motivated engagement with social practices which they value' and that 'space" is a constructive concept for understanding 
how learning occurs' (Gee, 2004: 77). This highlights the importance of the first language of the learner in the development of literacy in the second language.

A possible strategy of acknowledging linguistic diversity in multilingual contexts is the adoption of linguistically inclusive pedagogies such as translanguaging (see for example, Baker, 2011; Li, 2018). Such a strategy allows for the simultaneous use of more than one language in a single setting. In such a strategy, students can be allowed to employ their diverse African languages to make meaning and later for other academic roles such as reading and assessments. This is particularly important in the context of developing students' abilities to paraphrase, synthesise and acknowledge information from a variety of sources.

The predominance of academic culture conventions embedded in the English language render it seriously unfair to expect African language speaking students to master firstly, the language, then the subject content, then the disciplinary conventions, all at once. It is thus important for academics and institutions to understand such a context and its underlying factors lest they are viewed as agents in the reproduction of colonial narratives of education. In the context of epistemic violence in South African higher education (Heleta, 2016), characterised by a disregard for indigenous knowledge systems (the use of African languages for teaching and learning), it has therefore become important for institutions of higher learning to give preference to a mind-set that appreciates and embraces South Africa's multilingual reality by drawing on students' strongest languages while providing them with support to study through the medium of English (Carstens, 2015). Such a mindset calls for a paradigm shift from viewing 'language as a problem and placing value to 'language as a resource' (Joseph and Ramani, 2012). This is particularly significant in that through inclusivity and the embracement of all knowledge systems, the education is able to eliminate pedagogic dissonance that alienates the majority of the student body, which is constituted by African language speakers, thereby supporting access and success (Scott, 2017).

Thirdly, it is also important to highlight that academic language is 'no one's mother tongue, not even that of children of the cultivated class (Bourdieu, et al., 1994). It is a unique discourse characterised by a particular variety of English, not like the variety used in everyday general communication (Boughey, 2000; McKenna, 2010; Paxton and Frith, 2013). As such, even $1^{\text {st }}$ language speakers of English struggle with this particular discourse (Boughey, 2000) because of its association with technical and complex ways thinking and interpreting knowledge, necessary for successful learning (Gee, 2004). Successful learning in this particular context means the ability to communicate competently in an academic discourse, which encompasses reading, evaluating information, as well as presenting, debating and creating knowledge through both speaking and writing. These capabilities require knowledge of the community's epistemology, of the genres through which the community interacts, and of the conventions that regulate these interactions (Wingate, 2015).

Given that success at university is also linked to issues of their identity and power, of which language is central, students from wider ranging backgrounds entering both traditional and new spaces in higher education may feel constrained by conventional writing practices. For 
example, they may often become preoccupied with form and feel there is only one way; hence writing at university itself becomes a barrier. They may be inclined to view formal conventions as over-prescriptive and stifling and wish to challenge canonical writing requirements and practices (Bailey, 2018). It is therefore critical, in the context of the above, that universities adopt innovative and creative ways of assessing students, in particular the use of formative assessment methods and effective feedback methods. This can include formative assessments to evaluate learning such as engaging students on reflective writing on their experiences (Carroll, 2002), and 'writing from constrained sources' where 'students are required to generate academic texts in response to authentic or semi-authentic tasks which centre around limited number of academic source texts' (Nathan, 2006: 103).

There is also a need for academics to move away from assessment strategies that do not require students' active participation, and the duplication of assessment activities as because such practices hinder the stimulation of original thinking thus influencing acts of plagiarism. The curriculum and assignment design should facilitate the development of academic literacies in which plagiarism is discouraged and not rewarded. Further, academics could assess students understanding of plagiarism through an assignment that requires students to do in-depth research on plagiarism. Moreover, more time should be given for students' assessments, with academics monitoring the tasks and providing feedback indifferent phases, for example, checking students outlines for originality and giving students an opportunity to submit drafts. In these assessments, Turnitin and other plagiarism detection tools could be used as developmental tools and opposed to policing tools.

\section{Conclusion}

While institutions of higher learning have developed policies and adopted software such as Turnitin to curb plagiarism, it is also important that they invest resources in academic development initiatives targeted at both staff and students. The better approach is for universities to invest and focus on the development of students' academic literacy skills through an approach that acknowledges the linguistic repertoires that students bring to the classroom and the unique nature of disciplinary discourses and conventions. As such, writing centres and academic literacy development units could play a key role in this particular regard by collaboratively working with disciplinary experts and embedding their support in selected disciplinary modules. Literature shows that plagiarism can either be intentional or unintentional hence relying on a single approach, particularly punishment or sanctions as a means of curbing plagiarism, can be catastrophic to the image of the institution in relation to its academic integrity, opportunities of access and success, commitment to social justice, among other things. It is also important for South African universities to acknowledge and appreciate the different linguistic repertoires that students bring to the classroom by developing language policies that recognise multilingualism and the use of African languages as additional languages of teaching and learning. As Haggis (2006) points out, there is need for institutions of higher learning to look at how traditional practices and aspects of the curriculum affect 
academic literacy development, and make necessary adjustments. Software detection and sanctions do not constitute education but serve to propagate social injustices and inequalities in South African higher education.

\section{Author Biography}

$\mathrm{Dr} \mathrm{H}$. Ndebele is a lecturer at the Mangosuthu University of Technology. He holds a PhD from the University of KwaZulu-Natal and is an NRF Rated Researcher. His research interests are in the field of sociolinguistics, academic literacies, academic writing, language management and language policy in higher education.

\section{References}

Anney, V. N \& Mosha, M. A. 2015. Students plagiarism in higher learning institutions in the era of improved internet access: Case study of developing countries. Journal of Education and Practice, 6(13): 203-216.

Archer, A. 2010. Challenges and potentials for writing centres in South African tertiary institutions. South African Journal of Higher Education, 24 (4): 495-150.

Badke, W. 2007. Give plagiarism the weight it deserves. Online, 31(5): 58- 60.

Baker, C. 2011. Foundation of Bilingual Education and Bilingualism. Bristol, UK: Multilingual Matters.

Bailey, R. 2018. Student writing and academic literacy development at University. Journal of Learning and Student Experience, 1: 1-12.

Batane, T. 2010. Turning to Turnitin to fight plagiarism among university students. Educational Technology and Society, 13(2): 1-12.

Belter, R.W. \& du Pré, A. 2009. A Strategy to Reduce Plagiarism in an Undergraduate Course. Teaching of Psychology, 36(4): 257-261

Boughey, C. 2000. Multiple metaphors in an understanding of academic literacy. Teachers and Teaching: Theory and Practice, 6(3): 279-290.

Breen, L. \& Maassen, M. 2005. Reducing the incidence of plagiarism in an undergraduate course: The role of education. Issues in Educational Research, 15 (1): 1-16.

Carroll, J. 2002. A Handbook for Deterring Plagiarism in Higher Education. Oxford: Oxford Brookes University.

Carstens, A. 2012. Using literacy narratives to scaffold academic literacy in the Bachelor of Education: A pedagogical framework. Journal for Language Teaching, 46(2):9-25.

Carstens, A. 2015. Developing a multilingual mindset: Promoting the development and use of students' strongest languages and empowering them in English as the academic lingua franca. Inaugural Address, Intreerede Poleloyat/homišo.

Chrysler-Fox, P.D. \& Thomas, A. 2017. Managing plagiarism of South African honors students: Does an intervention have any effect? Original Research, 1-16. 
De Kock, T., Sayed, Y. \& Badroodien, A. 2018. Narratives of social cohesion: Bridging the link between school culture, linguistic identity and the English Language. Education as Change, 22(1): 1-29.

De-Jager, K. \& Brown, C. 2010. The tangled web: Investigating academics' views of plagiarism at the university of Cape Town. Studies in Higher Education, 35(5): 573-528.

Desai, Z. 2016. Learning through the medium of English in multilingual South Africa: enabling or disabling learners from low income contexts? Comparative Education, 52(3): 343-358.

Gee, J.P. 2004. Situated Language and Learning: A Critique of Traditional Schooling. New York and London: Routledge.

Haggis, T. 2006. Pedagogies for diversity: retaining critical challenge amidst fears of 'dumbing down. Studies in Higher Education, 31 (5): 521-535.

Hebb, J. 2002. Mixed forms of academic discourse: a continuum of language possibility. Journal of Basic Writing, 21 (2): 21-36.

Heleta, S. 2016. Decolonisation of higher education: Dismantling epistemic violence and eurocentrism in south Africa. Transformation in Higher Education, 1(1): 9-23.

Heugh, K. \& Skutnabb-Kangas, T. 2010. Multilingual Education Works: From the Periphery to the Centre. Delhi: Orient Blackswan.

Hornberger, N.H. 2003. Continua of biliteracy. In Hornberger, N.H. (ed.) Continua of Biliteracy: An Ecological Framework for Educational Policy, Research, and Practice in Multilingual Setting. Clevedon: Multilingual Matters, 3-34.

Jones, C., Turner, J. \& Street, B. 1999. Students Writing in the University: Cultural and Epistemological Issues. Amsterdam: Benjamins.

Joseph, M. \& Ramani, E. 2012. 'Globalization': Going beyond the dichotomy of global versus local through additive multilingualism. International Multilingual Research Journal, 6: 2234.

Leibowitz, B., Goodman, K., Hannon, P. \& Parkerson, A. 1997. The role of a writing centre in increasing access to academic discourse in a multilingual university. Teaching in Higher Education, 2(1): 5-19.

Li, W. 2018. Translanguaging as a Practical Theory of Language. Applied Linguistics, 39(1): 9-30.

Lillis, T. 2001. Student Writing Access, Regulation, Desire. London: Routledge.

Lillis, T. \& Scott, M. 2007. Defining academic literacies research: Issues of epistemology, ideology and strategy. Journal of Applied Linguistics, 4(1): 5-32.

Mahabeer, P. \& Pirtheepal, T. 2019. Assessment, plagiarism and its effects on academic integrity: Experiences of academics at a university in South Africa. South African Journal of Science, 115(11/12): 1-8.

Mainka, C. \& Raeburn, S. 2006. Investigating staff perceptions of academic misconduct: first results in one school. Proceedings of the 2nd international plagiarism conference. Newcastle: Northumbria Learning Press, 1-15. 
McKenna, S. 2010. Cracking the code of academic literacy: An ideological task. In Hutchings, C. and Garraway, J. (eds.) Beyond the University Gates: Provision of Extended Curriculum Programmes in South Africa. Grahamstown: Rhodes University, 8-14.

Mgqwashu E.M. 2014. On developing academic literacy in the mother tongue for epistemological access: the role of IsiZulu as the LoLT in a south African university. Current Issues in Language Planning, 15(1): 90-103.

Mothlaka, H.A. \& Makalela, L. 2016. Translanguaging in an academic writing class: Implications for a dialogic pedagogy. Southern African Linguistics and Applied Language Studies, 34(3): 251-260.

Mphahlele, A. \& McKenna, S. 2019. The use of Turnitin in the higher education sector: Decoding the myth. Assessment and Evaluation in Higher Education, 44(7): 1079-1089.

Mulcahy, S. \& Goodacre, C. 2004. Opening Pandora's box of academic integrity: Using plagiarism detection software. Proceedings from ASCILITE Conference 2004, Perth, WA.

Nathan, P. 2006. Teaching against plagiarism in the EAP classroom. In Beaven, B. (ed.). IATEFL 2006 Harrogate conference selections. Canterbury: IATEFL.

Noynaert, J.E. 1997. Plagiarism detection software. Available at: http://www.micsymposium.org/mics_2005/papers/paper97.pdf (accessed 17 July 2008)

Paxton, M. \& Frith, V. 2013. Positioning academic literacies at the core of curriculum design. Paper presented at the HELTASA conference, 26-29 November, UNISA, Pretoria.

Pineteh, E.A. 2012. Using virtual interactions to enhance the teaching of communication skills to information technology students. British Journal of Educational Technology, 43 (1): 85-96.

Pineteh, E.A. 2014. The Academic Writing Challenges of Undergraduate Students: A South African Case Study. International Journal of Higher Education, 3(1): 12-22.

Savage, S. 2004. Staff and students' response to a trial of Turnitin Plagiarism Detection Software. Proceedings of the Australian Universities Quality Forum, Sydney, Australia.

Scott I. 2017. Without success, access will fail. Mail and Guardian, 6 October. Available at: https://mg.co.za/article/ 2017-10-06-00-without-success-access-will-fail (accessed 12 August 2019).

Sentleng, M. P \& King, L. 2012. Plagiarism among undergraduate students in the faculty of Applied Sciences at a South African higher education institution. South African Journal of Libraries and Information Science, 78(1): 57-67.

Sharma, B.K. 2007. Plagiarism among university students: Intentional or Accidental? Journal of NELTA, 12 (1\&2): 134-140.

Sibomana, E., Ndayambaje, I. \& Uwambayinema, E. 2018. Plagiarism in higher education environment: Causes and solutions. Rwandan journal of education, 4(2): 15-23.

Singh, S. \& Remenyi, D. 2016. Plagiarism and ghostwriting: The rise in academic misconduct. South African Journal of Science, 112(5/6): 1-7.

Street, B. 2004. Academic literacies and the 'new Orders': Implications for research and practice in student Writing in higher education. Learning and Teaching in the Social Sciences, 1(1): 9-20. 
Van de Poel, K. \& Gasiorek, J. 2012. Effects of an efficacy-focused approach to academic writing on students' perceptions of themselves as writers. Journal of English for Academic Purposes, 11: 294-303.

Van Dyk, T. \& Van de Poel, K. 2013. Towards a responsible agenda for academic literacy development: Considerations that will benefit students and society. Journal for Language Teaching, 47(2): 43-70.

Wingate, U. 2015. Academic Literacy and Student Diversity. The Case for Inclusive Practice. Bristol: Multilingual Matters.

Wingate, U. 2006. Doing away with 'study skills. Teaching in Higher Education, 10(4): 457-469. 